\title{
The FRUITFULL MADS-box gene mediates cell differentiation during
}

\section{Arabidopsis fruit development}

\author{
Qing Gu1,*, Cristina Ferrándiz², Martin F. Yanofsky² and Robert Martienssen ${ }^{1, \dagger}$ \\ ${ }^{1}$ Cold Spring Harbor Laboratory, PO Box 100, Cold Spring Harbor, NY 11724, USA \\ 2Department of Biology and Center for Molecular Genetics, University of California at San Diego, La Jolla, CA 92093-0116, USA \\ *Current address: M409-WLS, Center for Legume Research and Division of Biology, University of Tennessee, Knoxville, TN 37996-0845, USA \\ †Author for correspondence (e-mail: martiens@cshl.org)
}

Accepted 6 February; published on WWW 18 March 1998

\section{SUMMARY}

Fruit morphogenesis is a process unique to flowering plants, and yet little is known about its developmental control. Following fertilization, fruits typically undergo a dramatic enlargement that is accompanied by differentiation of numerous distinct cell types. We have identified a mutation in Arabidopsis called fruitfull (ful-1), which abolishes elongation of the silique after fertilization. The ful-1 mutation is caused by the insertion of a DsE transposable enhancer trap element into the $5^{\prime}$ untranslated leader of the AGLS MADS-box gene. $\beta$ glucuronidase (GUS) reporter gene expression in the enhancer trap line is observed specifically in all cell layers of the valve tissue, but not in the replum, the septum or the seeds, and faithfully mimics RNA in situ hybridization data reported previously. The lack of coordinated growth of the fruit tissues leads to crowded seeds, a failure of dehiscence and, frequently, the premature rupture of the carpel valves. The primary defect of ful-1 fruits is within the valves, whose cells fail to elongate and differentiate. Stomata, which are frequent along the epidermis of wild-type valves, are completely eliminated in the ful mutant valves. In addition to the effect on fruit development, ful cauline leaves are broader than those of wild type and show a reduction in the number of internal cell layers. These data suggest that $A G L 8 / F U L$ regulates the transcription of genes required for cellular differentiation during fruit and leaf development.

Key words: ful, Fruit development, MADS-box gene, Cell division and expansion, Transposable enhancer trap, Arabidopsis thaliana

\section{INTRODUCTION}

The fruit, a plant organ mediating maturation and dispersal of the seed, is the end product of a successful fertilization process. Diverse forms of fruits are found in angiosperms, but in most plants the fruit consists of pericarp, which is derived from the ovary wall, and seeds, derived from the fertilized ovules. The fruits of over three thousand species of Brassicaceae, including Arabidopsis thaliana, are known as siliques and develop from a gynoecium consisting of two carpels that share a fused tissue called the septum (Rollins, 1993). On each side of the fruit the peripheral walls of the carpels, known as the valves, are joined to the replum, which is the outer margin of the septum (Fahn, 1967). The epidermis of the replum is visible as a suture that divides the two carpels, and it encases a vascular bundle that branches out into the placenta. After fertilization, the Arabidopsis gynoecium expands drastically to form an elongated silique in response to a hypothetical signal that emanates from the fertilized egg (Hensel et al., 1994). Upon maturation, a zone of dehiscence develops along the replum-valve junction such that the valves detach from the replum to release the seeds. Growth of the embryo, the ovules and the peripheral gynoecium valves involves cell differentiation and expansion and must be carefully coordinated during fruit development to generate the final form.

The cellular organization of the developing Arabidopsis gynoecium has been described previously (Hill and Lord, 1988; Okada et al., 1989; Sessions and Zambryski, 1995). The gynoecium arises from the center of the floral meristem (flower stage 6, as defined by Smyth et al., 1990) and forms a cylinder-like structure. At stage 9 , four distinct tissue types can be recognized on the surface of the gynoecium, namely the apical stigma, the style, the carpel valves and the narrow stretch of epidermis covering the replum. In elongated siliques, such as those of Arabidopsis, the ovules are attached by their funiculi to the replum. Four rows of ovules are positioned alongside two vascular strands in the Arabidopsis silique. Within the valve, six layers of cells are organized into a well-defined pattern, with outer and inner epidermis sandwiching four internal cell layers. Immediately after fertilization, profuse cell division and expansion initiate in the valves as well as in the septum, in order to accommodate the rapid growth of the developing seeds, and elongation of the fruit is most noticeable (Müller, 1961). Anticlinal cell divisions are predominant throughout the developing valve tissue resulting in a thin and elongated valve. A number of specialized cell types differentiate post- 
fertilization, such as stomatal cells in the valve epidermis (Bowman, 1994).

Many mutations affecting the gynoecium have been isolated in Arabidopsis. These mutations affect gynoecium specification (agamous: Bowman et al., 1989), patterning (clavata: Clark et al., 1993) and morphogenesis (ettin: Sessions and Zambryski, 1995; crabsclaw: Alvarez and Smyth, 1997; and tousled: Roe et al., 1997). Recently several mutants have been isolated that are capable of fruit development without fertilization processes, namely the fie (Ohad et al., 1996) and the fis (Chaudhury et al., 1997) mutants. However, few mutations affecting fruit development after fertilization have been studied (Okada et al., 1989).

Using transposon-mediated enhancer trap mutagenesis (Springer et al., 1995; Sundaresan et al., 1995), we have isolated a mutation that blocks elongation of the silique after fertilization. This restricted expansion results in a crowded silique full of seeds, and so the mutant was named fruitfull (ful1). Both cell expansion and differentiation are affected in the carpel valves, creating a zigzag pattern in the replum epidermis. Molecular characterization of the mutant revealed that the enhancer trap had caused a loss-of-function mutation in the previously reported AGL 8 gene (Mandel and Yanofsky, 1995). Here we show that the AGL 8 MADS-box gene is required for the normal pattern of cell division, expansion and differentiation during morphogenesis of the Arabidopsis silique.

\section{MATERIALS AND METHODS}

\section{Genetic screen}

Parental lines (all in Landsberg erecta (Ler) background) carrying an Ac transposase gene were crossed to lines carrying the Ds-GUS enhancer trap DsE and gene trap DsG (Sundaresan et al., 1995; Springer et al., 1995), to generate $F_{1}$ plants in which the Ds element transposed to new sites. The $\mathrm{F}_{2}$ seeds were screened for germinal transposants in MS medium (Carolina Biological Inc.) containing kanamycin $(50 \mu \mathrm{g} / \mathrm{ml})$ and $\alpha$-naphthalene-acetamide $(3.5 \mu \mathrm{M})$ (described in detail by Martienssen and Springer, 1997). The ful-1 mutant was identified in the enhancer trap line ET3214. Subsequently ful-1 was backcrossed to the wild-type Ler, and the following $\mathrm{F}_{2}$ population was checked for segregation. Normal and ful-1 plants segregated in a 3:1 ratio among $400 \mathrm{~F}_{2}$ progeny of the heterozygous backcrossed plants, indicating that the mutation was recessive. In all subsequent experiments the backcrossed progeny was used.

\section{Scanning electron microscopy}

Tissues from wild-type Ler and ful- 1 plants were fixed overnight at $4^{\circ} \mathrm{C}$ in FAA $(50 \%$ ethanol, $5 \%$ glacial acetic acid, $3.7 \%$ formaldehyde), dehydrated through an ethanol series and criticalpoint dried. Specimens were sputter-coated with gold and palladium (4:1) and examined in a Cambridge S360 scanning electron microscope using an accelerating voltage of $10 \mathrm{kV}$.

\section{Thin sectioning}

Young cauline leaves and floral organs of different stages from both ful- 1 and Ler plants were fixed in $2 \%$ glutaradehyde, and dehydrated through an ethanol series. The tissue was infiltrated with propylene oxide and embedded in Spurr's resin. $1 \mu \mathrm{m}$ sections were cut and stained in Toluidine Blue. In addition, some of the floral organs were first stained for GUS expression before embedding and sectioning. The term 'cross section' refers to those sections that are perpendicular to the apical-basal axis of the fruit.

\section{Characterization of the Ds insertion site}

The genomic DNA flanking the ful-1::Ds insertion was amplified using Tail-PCR (thermal asymmetric interlaced PCR). The procedure was followed exactly as described in Liu et al. (1995) and Tsugeki et al. (1996). The PCR products were purified using Qiagen columns (Cat. 81041) and sequenced on an ABI automatic DNA sequencer. After obtaining sequence information of the flanking DNA at the Ds $5^{\prime}$ site, the insertion site was analyzed by sequencing using primers AGL8-1 (5' ccacaaatatcatcgtc $\left.3^{\prime}\right)$, AGL8-2 (5' cagatagatatgatcgatgtg $3^{\prime}$ ) and the Ds primers (Tsugeki et al., 1996). A total of 570 base pairs of flanking DNA were sequenced. The coding sequence matched completely with the previously reported AGL8 cDNA sequence (Mandel and Yanofsky, 1995). 135 bp of the 5' upstream promoter region and $150 \mathrm{bp}$ of the first intron also matched the $A G L 8$ genomic sequence (C.F. and M.F.Y., data not shown).

\section{RNA blot analysis}

Poly(A) ${ }^{+}$RNA was isolated from Ler and ful- 1 plants using the Dynabeads Oligo(dT) 25 system (Dynal). RNA-blot analysis was done by established methods (Mandel and Yanofsky, 1995). The $A G L 8 / F U L$ probe contained the full-length cDNA.

\section{Genetic complementation}

ful-1 carpels were pollinated with pollen from plants homozygous for a 35S::AGL8 transgene (M. A. Mandel and M. F. Yanofsky, unpublished results). $F_{1}$ plants were allowed to self-pollinate, and GUS assays of $90 \mathrm{~F}_{2}$ plants were performed on cauline leaves to select plants carrying the ful- 1 allele. The expected segregation ratio of $3: 1$ GUS+:GUS- plants was observed. Among the 70 GUS+ plants, 43 had normal, elongated siliques, 9 showed typical ful-1 fruit morphology and 18 displayed a range of intermediate phenotypes. These numbers fit an 8:3:1 ratio and were therefore consistent with a single rescuing T-DNA locus. Five plants with intermediate phenotypes were allowed to self and were found to be ful-1 homozygotes. The presence of the 35S::AGL8 transgene in these five plants was confirmed by DNA-blot analysis (data not shown). The data were consistent with the conclusion that these intermediate phenotypes represented ful-1 homozygotes whose phenotype was partially rescued by the $35 \mathrm{~S}:: A G L 8$ transgene.

\section{Staining method}

Seedlings grown in MS medium and floral tissues collected from soilgrown plants were analyzed for their GUS expression patterns. The GUS solution contained $50 \mathrm{mM}$ sodium phosphate buffer, $\mathrm{pH} 7.0,1$ $\mathrm{mM}$ EDTA, $0.5 \mathrm{mg} / \mathrm{ml}$ 5-bromo-4-chloro-3-indolyl $\beta$-D glucuronic acid (X-Gluc, Rose Scientific Inc.), 0.4\% Triton X-100, $100 \mu \mathrm{g} / \mathrm{ml}$ chloramphenicol and $5 \mathrm{mM}$ each of potassium ferri/ferrocyanide. Samples were vacuum infiltrated, incubated at $37^{\circ} \mathrm{C}$ for $24-36$ hours, and depleted of chlorophyll in 70\% ethanol (Springer et al., 1995; Sundaresan et al., 1995). Some flower samples were embedded in paraffin after GUS staining. $8 \mu \mathrm{m}$ cross sections were made and viewed under dark-field microscopy.

\section{RESULTS}

\section{Isolation and mutant phenotype of fruitfull (ful-1)}

The ful-1 mutation was identified during a large-scale insertional mutagenesis using enhancer and gene trap Ds transposable elements (Sundaresan et al., 1995; Springer et al., 1995). This system utilizes the maize Ac/Ds transposable elements and the reporter gene GUS. Transposition events were selected and screened for reporter gene expression patterns and mutant phenotypes. ful- 1 was identified in the $\mathrm{F}_{3}$ progeny of an enhancer trap line (see Materials and methods). 


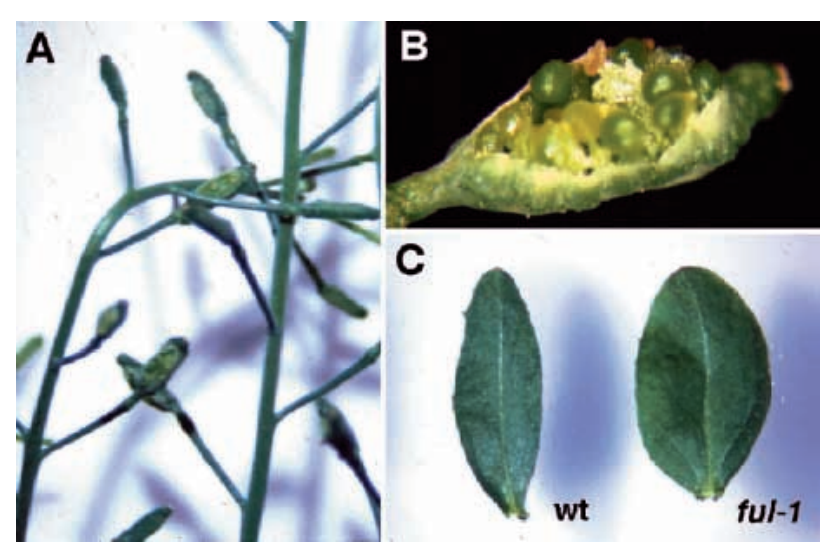

Fig. 1. Mutant phenotype of ful-1 plants. (A) The developing siliques on a 6-week-old ful-1 plant. (B) Example of the premature bursting of a ful-1 silique (about $3 \mathrm{~mm}$ in length). (C) A comparison of the cauline leaves of ful-1 and wild type (wt).

The most drastic effect of the ful- 1 mutation was observed in the silique that failed to elongate, with seeds tightly compressed inside, as shown in Fig. 1. Backcrossing to "wild type' Landsberg erecta (Ler) confirmed that ful- 1 is a recessive mutation (Materials and methods). To address whether the ful1 mutation was caused by the insertion of the Ds-GUS enhancer trap element (DsE), we analyzed co-segregation between the mutant phenotype and expression of the GUS reporter gene. Among a total of 200 mutant plants all were GUS positive, and one-third of the wild-type plants were GUS negative, as expected in the case of complete linkage between the GUS reporter and the mutation. Genomic DNA analysis showed that the mutant plant carried a single transposed Ds element, as expected (data not shown).

Seeds in the mutant plants looked normal except for a smaller size, and they remained arranged in four rows as in the wild type. However they were highly compacted inside the silique. Compared with Ler siblings, the number of seeds in each silique of ful-1 mutants was reduced by $25 \%$, and the dry weight of each ful-1 seed was reduced by $30 \%$ (data not shown), while the length of the silique was reduced by more than $80 \%$ (Fig. 2). Frequently we observed a dramatic phenotype of the seeds bursting out of the siliques a few days after fertilization (Fig. 1B), whereas in normal siblings dehiscence occurred much later, by an orderly separation at the junction between the replum and the valves once the silique was mature. Additionally, the wild-type siliques elongated at a steady rate after pollination, and by day 5 the silique had elongated nearly eightfold compared to the size before pollination (Fig. 2). In contrast the ful- 1 siliques had expanded merely twofold by 20 days after pollination (Fig. 2). Another phenotype observed in the ful- 1 plants is that the cauline leaves are wider than those of wild-type siblings (Fig. 1C).

\section{Differentiation of the valve epidermis}

Since the ful mutation most dramatically affected the shape of the silique, we investigated ful- 1 silique development in detail. Floral organs in ful-1 mutants developed normally during early stages (data not shown). At stage 12, still prior to fertilization, the surface of the gynoecium had already differentiated into

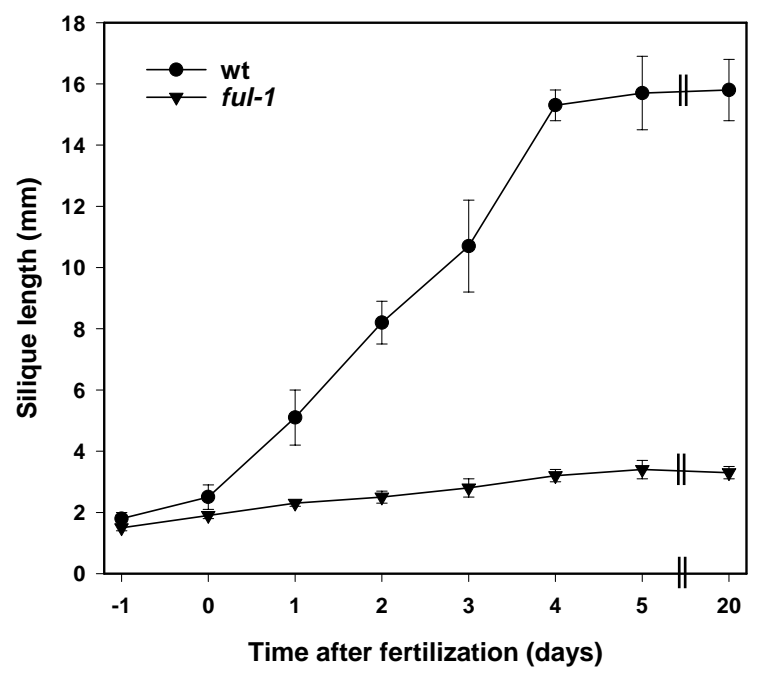

Fig. 2. Elongation rate of the silique following fertilization. Averages for 3-5 siliques are given for each time point for both wild type (wt, Ler) and mutant (ful-1). Standard errors are indicated by bars. Day -1 , the day before fertilization, (flower stage 12, according to Smyth et al., 1990). Day 0, the day of fertilization (flower stage 13). Days 120 , number of days after fertilization (stages 14-20).

stigma, style and valves. In Ler, which will be referred to as 'wild type', the carpel valve epidermal cells are small and stomatal precursors can already be identified by their shape. The demarcation between the valves becomes readily distinguishable. However, in the valve epidermis of ful-1 mutants, cells were smaller and uniformly arranged, and there were no stomatal precursor cells. The demarcation between the valves and the replum epidermis was not visible. In contrast to the situation in the valves, the ful- 1 mutant epidermal tissues in stigma and style were indistinguishable from wild type and displayed normal cuticular thickening and interspersed stomata.

Immediately after fertilization (stage 13), the epidermal cells in the wild-type valves become irregular in shape and larger than the replum epidermal cells. Stomata begin to form in the carpel valve epidermis. The differences between the wild-type and the ful- 1 carpel epidermal cell morphology became more dramatic from this stage onwards and were particularly evident following stage 15 , as revealed by scanning electron microscopy (Fig. 3). Whereas the stigmatic tissue and the style resembled those in the wild type (Fig. 3D), cell differentiation in the replum and valves in the ful- 1 mutants did not proceed

Table 1. Epidermal cell numbers in valve cross sections

\begin{tabular}{lccc}
\hline & Stage* $^{*}$ & Inner epidermis $\dagger$ & Outer epidermis $\neq$ \\
\hline ful-1 & 12 & $54 \pm 4$ & $150 \pm 2$ \\
Wild type & 12 & $23 \pm 3$ & $145 \pm 3$ \\
ful-1 & 16 & $63 \pm 4$ & $160 \pm 6$ \\
Wild type & 16 & $27 \pm 4$ & $152 \pm 2$
\end{tabular}

*Valves of ful-1 and wt (Ler) at the flower stages 12 (prior to fertilization) and 16 (after fertilization) were compared.

$\dagger$ Inner epidermal cells of one valve excluding the replum.

$\ddagger$ Outer epidermis covering both valves and replums. Average number \pm s.d. from three thin sections each of two silique samples are given. 
normally (Fig. 3E). The epidermal cells covering the valves failed to expand and stomatal cells failed to develop (Fig. 3F), while in the wild type, functional stomata were present in high numbers (Fig. 3C). Interestingly, in the ful-l mutants the epidermal cells of the replum continued to expand but not in the direction of the silique main axis; instead they adopted irregular and more rounded shapes (Fig. 3K). The differences between wild-type and ful- 1 siliques became more evident as fruit development proceeded. Whereas the wild-type valve cells continued to grow rapidly, ful- 1 valve cells apparently stopped growing altogether (Fig. $3 \mathrm{~K}$ and below). Outer epidermal cells of the replum continued to expand and grew to approximately the same length as in the wild type, but instead of forming parallel rows of cells, they adopted a wavy zigzag arrangement, almost perpendicular to the main axis of the fruit (Fig. 3K). This mediated a modest lateral growth of the silique and accommodation of the growing seeds.

\section{Cell division and expansion}

We further analyzed the cellular organization of the carpel valves in transverse sections. It was noticed that there were more than twice as many cells in the inner valve epidermis in the mutant as in normal siblings (Fig. 4A,C and Table 1), indicating a failure in cell division control. This alteration had occurred even before anthesis, such that twice as many small cells were observed in the mutant inner epidermal layer (Fig. 4A and Table 1). The outer epidermis of the ful-l valve had a similar number of cells to the wild type (Fig. 4A,C and Table 1), but cell expansion did not occur in the mutant after fertilization (Fig. 4C). The replum epidermis consists of 10 files of narrow rectangular cells in the wild type, and a similar number of cell files was observed in the ful-1 replum (data not shown). After fertilization, cell size increased rapidly in normal valves, in both the apical-basal and transverse dimensions. However, cell expansion was not observed in either axis in the ful- 1 mutant valve (Figs $3 \mathrm{~K}, 4 \mathrm{C})$. Interestingly, the septum of the ful1 mutant appeared to follow a separate pathway, and was seemingly capable of responding to signals for growth and differentiation after fertilization. The septum cells divided and expanded, progressively filling up all the space in the ovary together with the developing seeds (Fig. 4C and data not shown). Medial and lateral vascular bundles throughout the valves were reduced in size and poorly differentiated (Fig. 4E), while the vascular bundles in the replum between the two valves appeared normal (Fig. 4A,C). However the exact nature of the defect in the vascular tissue was unclear. The poor differentiation of the vascular bundles did not allow us to distinguish whether specific vascular cell types were missing.

\section{Cauline leaf shape and midvein differentiation}

In addition to the defective silique, ful- 1 plants also had more rounded cauline leaves, and this phenotype cosegregated with
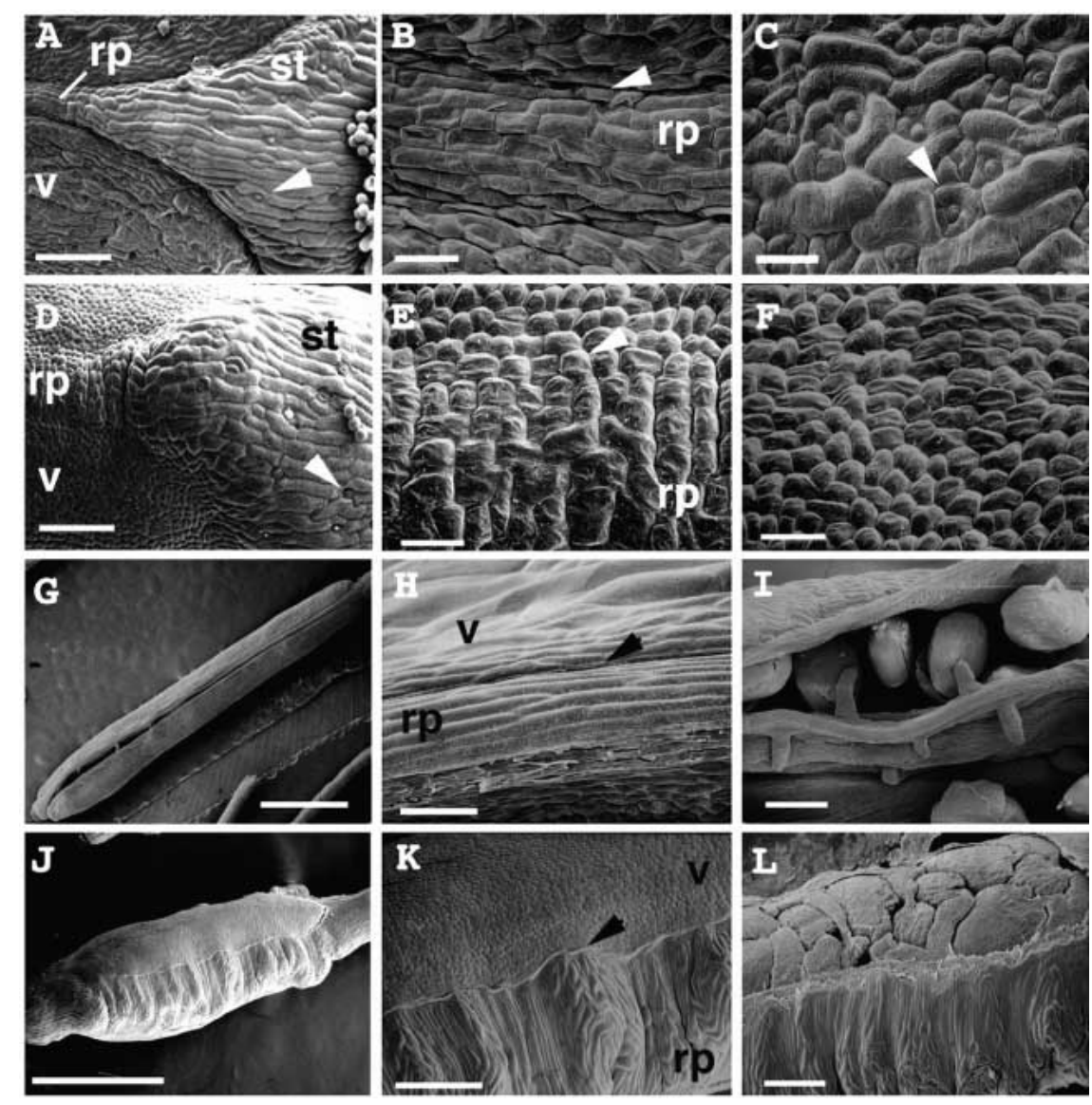

Fig. 3. Scanning electron micrograph of wild-type (A-C, G-I) and ful-1 (D-F, J-L) fruits. (A) Stage 15 wild-type gynoecium at the junction between style (st), replum (rp) and valve (v) regions. Note stomata in style epidermis (arrowhead). (B) Close-up of the medial side of the carpel in A. The demarcations between the valves and replum are clearly visible (arrowhead). (C) Close-up of the lateral side of the carpel in A. Note stomatal cells (arrowhead). (D) Stage 15 ful- 1 gynoecium in a similar view to that in A. The style cells appear wild type and stomata are present (arrowhead). Note poorly developed valve epidermis. (E) Close-up of the medial side of the carpel in D. Note the irregularly shaped replum epidermal cells. The demarcation between this region and the valve (arrowhead) is not well defined. (F) Close-up of the lateral side of the carpel in D. Cells in the valve epidermis are small, unorganized and lack stomatal cells. (G) Stage 18 wild-type silique ( $9 \mathrm{~mm}$ in length). Dehiscence of the valves has begun. (H) Close-up of the silique in G. Cells in the valve (v) and in the replum (rp) have greatly elongated and are arranged along the silique main axis. Note the zone of dehiscence (arrowhead).

(I) Medial view of a dehiscent wild-type silique. The replum is a flat layer and seeds are arranged in rows. (J) A ful-1 silique (stage 18, about $3 \mathrm{~mm}$ in length). The replum region is broad and the cells adopt a wavy, zigzag pattern. (K) Close-up of the silique in J. Dehiscence fails to take place (arrowhead). The replum cells are similar to wild-type, although they are mainly arranged perpendicular to the main axis of the fruit. The epidermal cells of the valve remain small and undifferentiated. (L) The valve has been removed from a ful -1 silique to show the dense packing of seeds inside the fruit. Bars, $100 \mu \mathrm{m}$ (A,D); $20 \mu \mathrm{m}$ (B,C,E,F); 2 mm (G); $50 \mu \mathrm{m}$ (H); $200 \mu \mathrm{m}$ (I,K,L); 1 mm (J). 
the small silique phenotype, shown in Fig. 5. Cross sectioning of the leaf tissue showed that the cells in the ful- 1 cauline leaf appeared loosely packed and disorganized (Fig. 5D). The mutants had only 4-5 internal cell layers, instead of 5-6 cell layers in the wild type (Fig. 5C, D). Also, the midvein in the cauline leaves of ful- 1 was found to be less developed in that there were fewer vascular cells in cross section of the developing ful- 1 cauline leaves than in normal leaves (Fig. 5D).

\section{Analysis of the ful::Ds insertion site and genetic complementation}

Sequencing revealed that the Ds element had inserted into the untranslated leader of the AGL8 gene (Fig. 6A), which had been previously cloned and sequenced by virtue of its homology to MADS-box transcription factors (Mandel and Yanofsky, 1995). Using a probe from the coding region, $A G L 8 \mathrm{mRNA}$ was not detectable in flowers from homozygous ful-1 mutant plants on RNA gel blots (Fig. 6B). Thus, the DsE insertion had abolished $A G L 8$ gene expression, suggesting that ful-1 leads to a complete loss of AGL8 function. DNA sequence analysis further revealed that the DsE insertion had resulted in alterations of the nucleotides at both ends of the DsE element (Fig. $6 \mathrm{~A})$. For this reason, the DsE element could not be remobilized.

To further confirm that the observed phenotypes were caused by the DsE insertion into $A G L 8$, we tested whether the $A G L 8 \mathrm{cDNA}$ was able to rescue the ful-1 mutant phenotype. Transgenic plants carrying the $A G L 8$ cDNA under the control of the strong CaMV35S promoter, were crossed with ful1 mutants (see Materials and methods). Carpels of homozygous $\mathrm{F}_{2}$ ful- 1 plants that contained the 35S::AGL8 transgene displayed a significant elongation of the valves, although some aspects of the ful-l silique were still observed, such as a wavy arrangement of the replum epidermal cells. Typical examples of these phenotypes are shown in Fig. 7. A closer inspection of these siliques showed the initiation of stomata differentiation in the valve epidermis (data not shown), which was never observed in ful-1 mutant plants. These results demonstrate that the $35 \mathrm{~S}:: A G L 8$ transgene can partially rescue the ful- 1 mutant phenotype. The absence of a full rescue may reflect a difference in the level or the timing of AGL8 and $35 \mathrm{~S}$ promoters within the carpel valves. Finally, in the wild-type background $35 \mathrm{~S}:: A G L 8$ expression resulted in very subtle changes in their appearance, including occasional early flowering (data not shown).

\section{The gene expression pattern of $F U L$}

Because the enhancer trap had landed in the $5^{\prime}$ untranslated region of the $A G L 8 / F U L$ gene, it was possible to analyze the endogenous gene expression pattern by monitoring the GUS reporter gene expression. We compared expression of the AGL8 gene in Ler (Mandel and Yanofsky, 1995) with expression of the GUS reporter gene driven by the enhancer trap element in homozygous ful-1 mutant and in heterozygous plants. It has been previously shown by RNA blots that $A G L 8$ is expressed in the stem and cauline leaves, and strongly expressed in the flowers, but not in the roots (Mandel and Yanofsky, 1995). We found that the GUS expression pattern faithfully mimics the AGL8 expression revealed previously by RNA gel blot and in situ hybridization (Mandel and Yanofsky, 1995). The most intense staining was seen in the inflorescence meristem (Fig. 8B,C) and in the carpel valves (Fig. 8B,D-G). GUS was localized to the vascular tissue of the stem and cauline leaves (Figs 8B, 5A,B), but not in the roots (Fig. 8A), or the vegetative shoot apical meristem or in the hypocotyl (data not shown).

In addition to the results matching those of prior RNA analysis, we showed that after fertilization, GUS accumulation
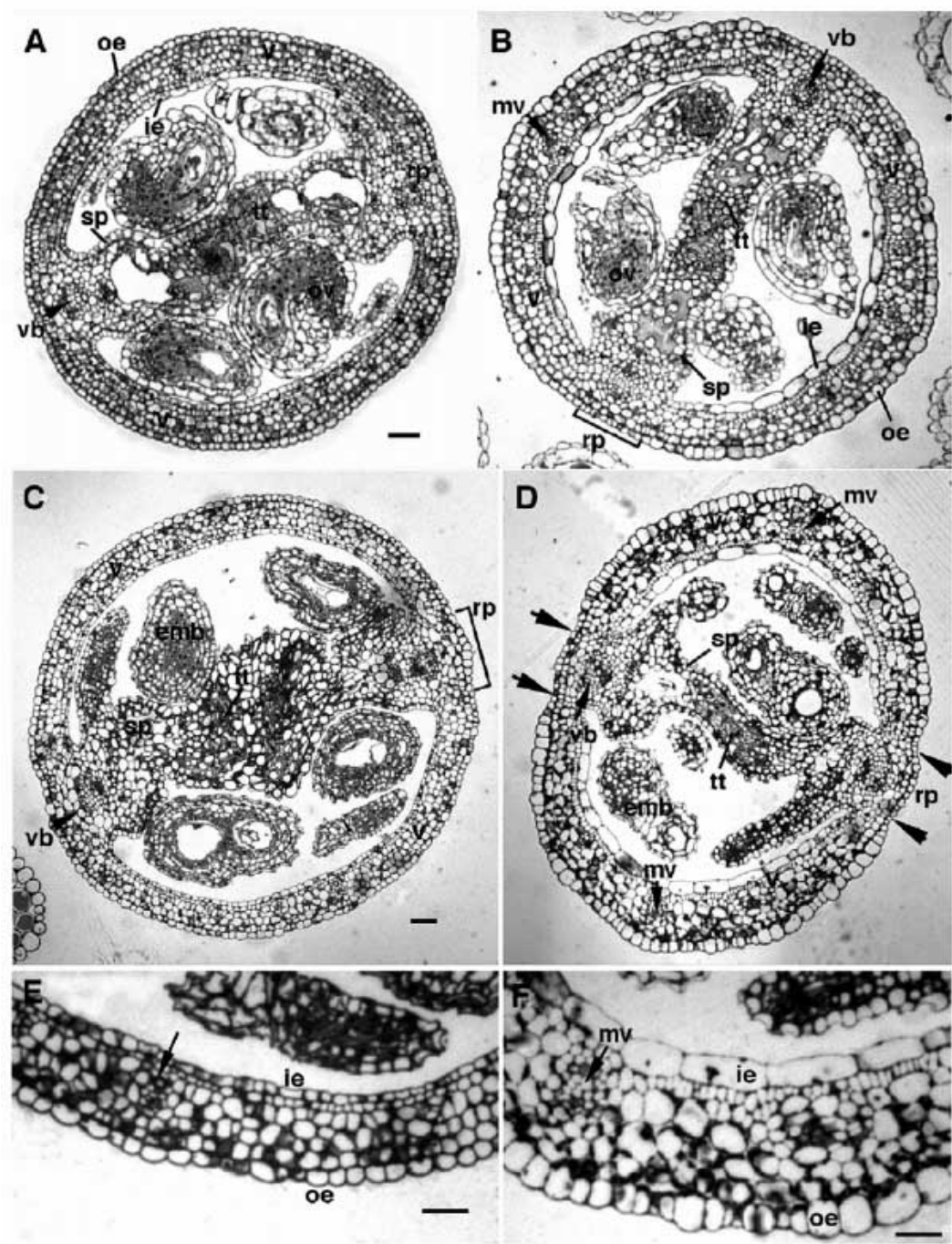

Fig. 4. Medial transverse cross sections of fruits before (stage 12) and after fertilization (stage 16). (A) ful-1, stage 12. (B) Ler, stage 12. (C) ful-1, stage 16. (D) Ler, stage 16. (E) and (F) are enlargments of parts of $C$ and $D$, respectively. The dehiscence zones are indicated by arrowheads. The arrow in $\mathrm{E}$ points to a poorly differentiated vascular bundle in the ful- $l$ valve. ie, inner epidermal cells; oe, outer epidermal cells; ov, ovule; rp, replum; sp, septum; tt, transmitting tract; vb, replum vascular bundle; v, valve; mv, valve medial vascular bundle; emb, developing embryo. Bars, $50 \mu \mathrm{m}$. 

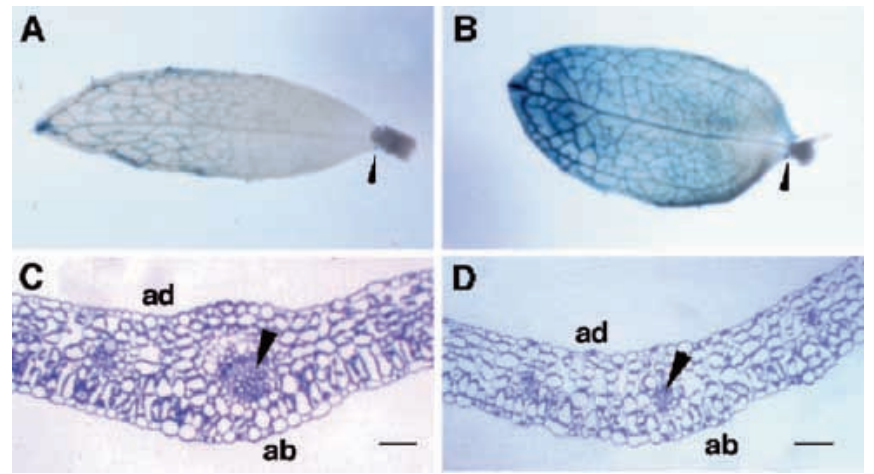

Fig. 5. Cauline leaf phenotype and GUS localization pattern. (A) Heterozygous (ful-1/+) and (B) homozygous (ful-1 mutant) cauline leaves, at about $1 \mathrm{~cm}$ in length. Both were stained for GUS expression. Arrowheads point to the stipules at the base of the leaf with GUS staining. (C, D) Medial transverse thin sections of wildtype and ful-1 young cauline leaves respectively. Arrowheads point to the mid vascular bundles. ad, adaxial side of the leaf; ab, abaxial side of the leaf. Bars, $50 \mu \mathrm{m}$.

in the carpel appeared to become confined to the apical and basal parts of the valves, but GUS activity was undetectable in mature brown fruit (after stage 17, data not shown). In transverse sections of the flower, GUS staining was confined to all cell layers of the valves, but was absent from the replum, the septum and the transmitting tract (Fig. 8E-G). Strong reporter gene expression was also observed in cauline leaves (Fig. 5A,B). Our analysis further revealed that GUS expression in homozygous mutant plants was first detected in the most distal vascular tissue of the cotyledons and the first pair of emerging leaves (Fig. 8A). GUS expression was also evident in the style and the vascular tissue of the sepals and inflorescence stems (Fig. 8B,D). GUS was also found in stipules (Fig. 5A,B) and in the nectaries of the flower (data not shown). The pattern of GUS accumulation in the ful-1/+ heterozygous siblings was weaker but qualitatively similar to that found in ful-l homozygous mutant plants (data not shown).

\section{DISCUSSION}

MADS-box proteins are a class of DNA binding regulatory proteins that are evolutionarily conserved among eukaryotes (Theißen and Saedler, 1995; Purugganan et al., 1995). A large number of key regulators involved in flower development are MADS-box genes that specify floral meristem identity or floral organ identity, including AGAMOUS, APETALA1, APETALA3, CAULIFLOWER and PISTILLATA in Arabidopsis (Yanofsky et al., 1990; Mandel et al., 1992; Jack et al., 1992; Kempin et al., 1995; Goto and Meyerowitz, 1994), and their orthologs in Antirrhinum and other species (Schwarz-Sommer et al., 1990). These proteins share a conserved DNA-binding MADS-domain at their amino termini. In addition to the five MADS-box genes defined by mutations, at least 20 additional members of the family have been isolated in Arabidopsis. The expression patterns of these genes suggest that they play diverse roles in plant development (Rounsley et al., 1995). We have identified a loss of function allele for the $A G L 8$ gene, and determined that it has an important role in fruit morphogenesis.

\section{FUL/AGL8 is widely expressed during plant development}

Analyses of the FUL::GUS reporter fusion revealed that the FUL gene is weakly expressed in rosette leaves during vegetative development and is subsequently strongly upregulated in the shoot apex upon the transition to flowering. Throughout inflorescence development GUS activity remains strong in the floral shoot apex and in the vascular tissues of the cauline leaves. High levels of GUS activity are also apparent in the central dome of young flower primordia, beginning at around stage 3 . Subsequently, GUS activity is observed in developing carpels, where strong expression becomes localized to the valves of the carpels and resulting fruits. In addition, GUS expression was detected in the style, as well as in nectaries and stipules. The observed FUL::GUS expression pattern is in close agreement with previous RNA gel blot and in situ hybridization analyses (Mandel and Yanofsky, 1995). Furthermore, we have localized FUL expression in vascular tissues during vegetative development, which had not been analyzed previously. In addition it is clear from our cross sections that FUL/AGL 8 is not expressed in the replum and other organs within the gynoecium (Fig. 8E$\mathrm{G})$.

In the gynoecium, $F U L$ is expressed at a high level in the valves, and it is the carpel valves that show the most striking mutant phenotype in homozygous ful- 1 mutant plants. Although FUL is expressed at high levels in inflorescence apices, scanning electron microscopy failed to uncover any alterations in inflorescence or floral meristems in the mutant plants (data not shown). Thus, our data suggest that $F U L$ is only required for normal fruit and cauline leaf development despite its widespread expression pattern. One possibility is that, if $F U L$ plays a role in vegetative and inflorescence development, it may be redundant with one of the other MADS-box genes whose expression pattern is known to overlap with that of FUL/AGL8 (Rounsley et al., 1995).
A

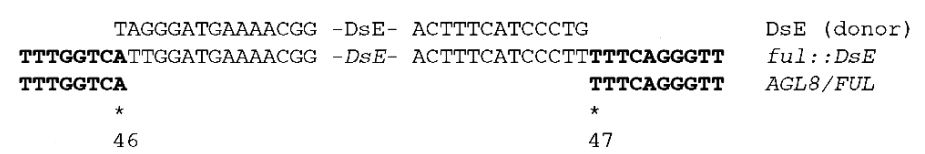

B

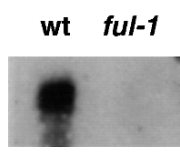

Fig. 6. Diagram of the DsE enhancer trap position (A) and RNA blot analysis of $F U L$ expression (B). (A) The DsE element is inserted into the $5^{\prime}$ untranslated region of the $F U L$ gene, at the position between 46 and 47 of the transcribed nucleotide sequence of the AGL8 gene (Mandel and Yanofsky, 1995). The ends of the DsE element are drawn, and the bold letters denote the sequence of the $A G L 8$ gene. (B) $2 \mu \mathrm{g}$ of poly(A) ${ }^{+}$RNA from aerial tissues of 20-day-old wild-type Ler (wt) and ful-1 plants were loaded, blotted and probed with an $A G L 8 / F U L$ cDNA probe. 


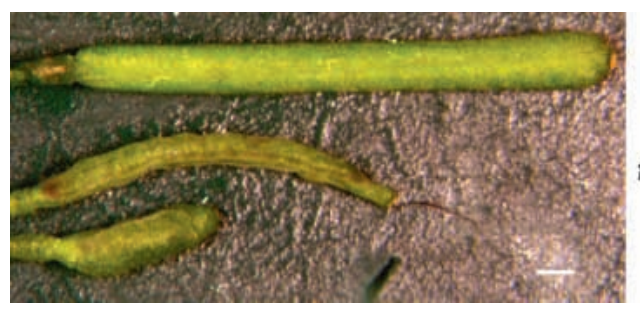

wt

ful-1, 35S::AGL8

ful-1

Fig. 7. Genetic complementation. Wild-type Ler (top), ful-1; 35S::AGL8 (middle) and ful-1 (bottom) mature siliques at stage 17 (about 3 days after fertilization). Bar, $1 \mathrm{~mm}$.

\section{FUL inhibits cell division and promotes cell expansion in the valve}

The Ler silique elongates by a factor of 8 after fertilization, while the ful- 1 silique has essentially lost the ability to extend, resulting in a short silique with overcrowded seeds. The primary defect responsible for this phenotype is a failure of cell differentiation and cell growth in the carpel valves. After fertilization, all cell types in mutant valves ceased to expand, the vascular tissue developed poorly and stomatal cells did not form in the valve epidermis. Strikingly, only the valves were affected and not the replum, which continued to grow and was forced into a zigzag pattern as a result. Although the most obvious defects occurred after fertilization, cell shapes were already distorted in mutant valves even before pollination. This was most obvious in the inner epidermis of the valves, which consisted of numerous tiny cells in the mutant as compared to fewer enlarged cells in the wild type. Thus, $F U L$ has multiple functions during cell differentiation, being able to promote cell expansion as well as inhibit cell division in specific cell types.

\section{FUL and the role of cell-cell interactions in fruit development}

Fruit development in Arabidopsis is induced by the successful fertilization of the female gametophyte. Although Arabidopsis plants are able to undergo limited seed development without fertilization in certain mutant backgrounds (Ohad et al., 1996; Chaudhury et al., 1997), under normal conditions signals must communicate between the fertilized gametophyte and the valve tissues (Hensel et al., 1994), possibly via the replum. The ful$l$ carpel lacks most aspects of the complex response of the wild type to the fertilization signal. This, together with the fact that $F U L$ is expressed in all cell layers of the carpel valves before and after fertilization, suggests a role for $F U L$ in establishing competence of these cells to respond to a signal provided by the fertilization process.

The nature of this signal is not known but could involve plant hormones. It is known from work in other species, such as tomato, that ethylene, auxins, cytokinin and gibberellins follow elaborate changes during early fruit development (reviewed by Gillaspy et al., 1993). However, spraying ful-1 mutant flowers
Fig. 8. GUS histochemical localization patterns in ful-1 plants. (A) An 11-dayold ful-1 seedling. (B) An inflorescence. The blue color represents the GUS localization. In addition, a few flower buds were dissected away to reveal GUS accumulation in the ful- 1 floral meristem, indicated by the arrow. (C, D). Dark-field microscopy showing the GUS localization in the inflorescence apical meristem (left in C), stage 6 gynoecium (right in C), and stage 10-12 carpel valves (D). (E-G) GUS localization in thin cross sections $(1 \mu \mathrm{m})$ of ful-1 mutant fruits. ie, inner epidermal cells; oe, outer epidermal cells; rp, replum; ov, ovule; sp, septum; $\mathrm{tt}$, transmitting tract; $\mathrm{v}$, valve; vb, replum vascular bundle. (E) Medial transverse cross section of a GUSstained carpel was sectioned and counter-stained in Toluidine Blue. (F) Enlargement of the upper left area of A. GUS activity is reflected by the blue speckles that accumulate in all cell layers of the valve. (G) A similar thin section to A, but without Toluidine Blue staining.
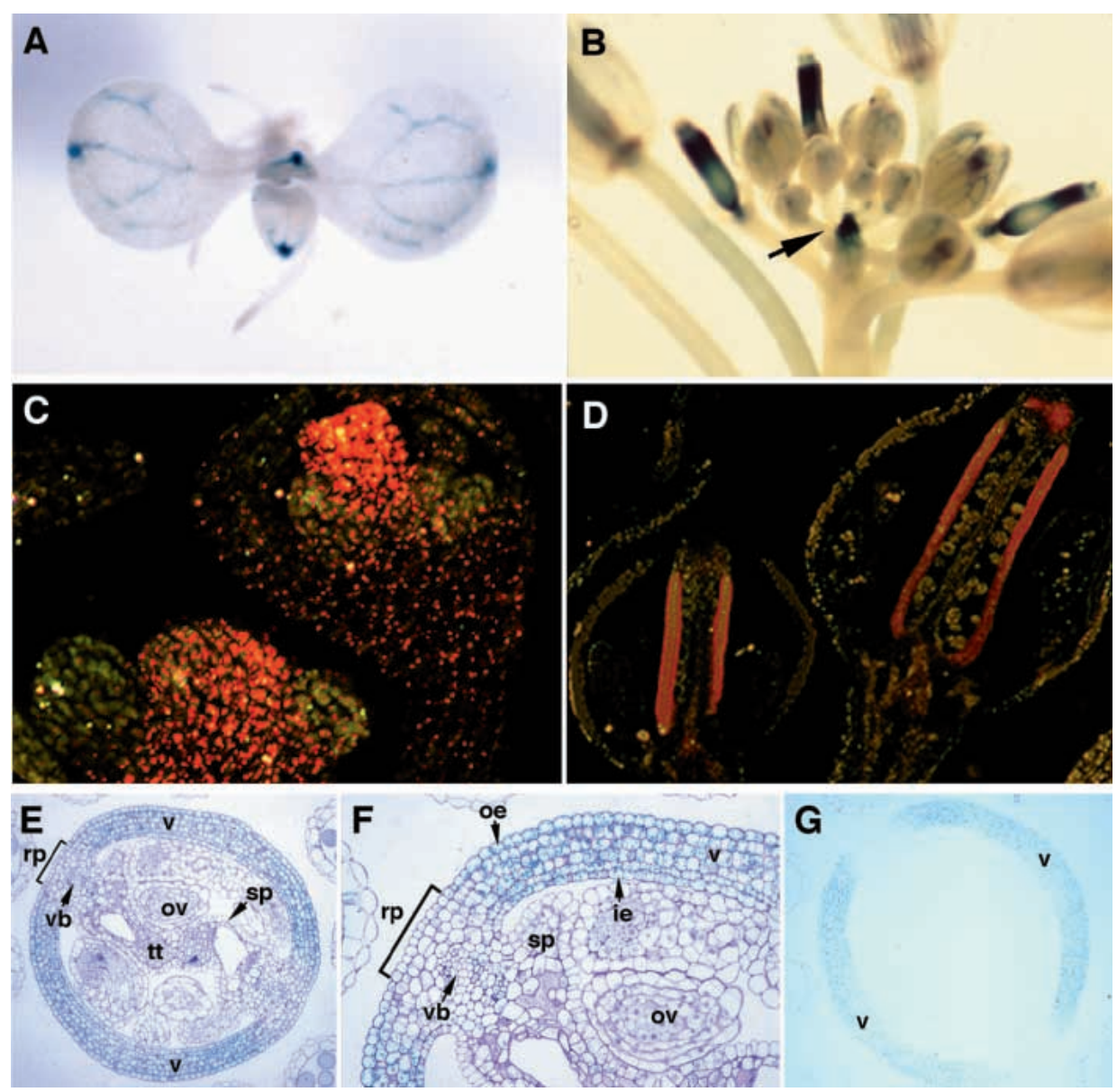

G 
with gibberellic acid, cytokinin or auxin did not rescue the ful1 phenotype (data not shown), suggesting that the defect in ful1 mutants is not simply a deficiency in these hormone levels, although it might be a lack of sensitivity to the hormones.

In wild-type carpels, FUL gene expression could not be detected in the replum or in the septum. Further, the lack of FUL expression in mutant valves often causes a failure of replum tissues to separate normally during dehiscence. This suggests that FUL may regulate the transcription of a cell-cell interaction factor required for dehiscence in the neighboring replum. Alternatively, cell-to-cell movement of the FUL protein itself may be directly responsible for cooperation between growth of the valves and of the replum. Cell-cell trafficking of MADS-box transcription factors has been implicated in coordination between cell layers in floral meristems (reviewed by Hake and Char, 1997), and failure to coordinate growth may result in subtle alterations in replum architecture leading to a failure of dehiscence. Dehiscence (pod shattering) in Brassica species is agronomically important because of seed loss at harvest (Petersen et al., 1996), suggesting that FUL may be of some value in manipulating this trait.

\section{Vascular development in the cauline leaf}

Outside the floral organs, FUL is expressed widely in the vasculature of vegetative tissues, although at a lower level. Detection of $A G L 8 / F U L$ mRNA by RNA gel blot in vegetative tissues (Mandel and Yanofsky, 1995) argues against an artifact of the promoter GUS fusion system. Our GUS fusion data extend previous findings because we have localized FUL gene expression to the vascular tissues. A mutant phenotype was observed only in ful-1 cauline leaves, which were broader and more rounded than in wild type, with the internal cell layers more loosely packed. It has recently been shown that the cell number in leaves of the angustifolia (an) and rotundifolia (rot) leaf shape mutants is the same as in wild type, indicating that leaf shape in these mutants is regulated by expansion polarity genes (Tsuge et al., 1996). The overall number of cells in the ful- 1 cauline leaf may also be the same as in wild type, so that the fewer layers of more loosely packed cells in the mutant may contribute to the broader shape of the leaf.

Alternatively, FUL may control cauline leaf shape through an effect on midvein differentiation. The diameter of the midvein is considerably reduced in ful- 1 cauline leaves, and the vein and surrounding tissues appear to be less developed than the tissue of wild type (Fig. 5C,D). midribless ( $\mathrm{mbl}$ ) mutants in Panicum (Fladung et al., 1991) and in pearl millet (Rao et al., 1988) have poorly differentiated midveins, and have broader leaves than normal. Interestingly, these mutants also have reduced carpels. Similarly, ovaryless (ovl) mutants of barley lack both ovaries in the flower and fully differentiated midveins in the vegetative leaves (Seip and Tsuchiya, 1979). Although carpel morphology is much more severely affected in these grasses than in ful-1 Arabidopsis, the phenotypes may be related. For example, midribless and ovaryless mutants in grasses result in partially indeterminate floral meristems (Fladung et al., 1991). The AGL8/FUL gene is strongly expressed in inflorescence meristems and may contribute to determinancy along with related MADS-box genes APETALA1 and CAULIFLOWER in Arabidopsis (C. F., Q. G., R. M. and M. F. Y., unpublished results).
We thank M. Lodhi, N. Kaplan and W. R. McCombie of the Lita Annenberg Hazen Genome Center at CSHL for DNA sequencing, A. von Arnim for critical reading of the manuscript and helpful suggestions, and M. Timmermans and T. Nelson for discussions on midribless mutants in grasses. Q. G. would like to acknowledge G. Stacey for supporting the completion of this work in his laboratory. This work was funded by NSF grant MCB- 9408042 to R. M., NSF grant IBN-9418436 to M. F. Y. Q. G. is a recipient of a NRSA postdoctoral fellowship from NIH. C. F. is a recipient of a postdoctoral fellowship from the Spanish MEC. R. M. acknowledges the generous support of David L. Luke III.

\section{REFERENCES}

Alvarez, J. and Smyth, D. R. (1997). Carpel development genes in Arabidopsis. Flowering Newsletter 23, 12-17.

Bowman, J. L. (1994). Pollination. In Arabidopsis: An Atlas of Morphology and Development. (ed. J. Bowman), pp. 346-347. Spinger-Verlag: New York.

Bowman, J. L., Smyth, D. R. and Meyerowitz, E. M. (1989). Genes directing flower development in Arabidopsis. Plant Cell 1, 37-52.

Chaudhury, A. M., Ming, L., Miller, C., Craig, S., Dennis, E. S., and Peacock, W. J. (1997). Fertilization-independent seed development in Arabidopsis thaliana. Proc. Nat. Acad. Sci. USA 94, 4223-4228.

Clark, S. E., Running, M. P. and Meyerowitz, E. M. (1993). CLAVATA1, a regulator of meristem and flower development in Arabidospis. Development 119, 397-418.

Fahn, A. (1967). Plant Anatomy. Pergamon Press: Oxford, New York.

Fladung, M., Bossinger, G., Roeb, G. W. and Salamini, F. (1991). Correlated alterations in leaf and flower morphology and rate of leaf photosynthesis in a midribless mutant of Panicum maximum Jacq. Planta 184, 356-361.

Gillaspy, G., Ben-David, H. and Gruissem, W. (1993). Fruits: A developmental perspective. Plant Cell 5, 1439-1451.

Goto, K. and Meyerowitz, E. M. (1994). Function and regulation of the Arabidopsis floral homeotic gene PISTILLATA. Genes Dev. 8, 1548-1560.

Hake, S. and Char, B. R. (1997). Cell-cell interactions during plant development. Genes Dev. 11, 1087-1097.

Hensel, L. L., Nelson, M. A., Richmond, T. A. and Bleecker, A. B. (1994) The fate of inflorescence meristems is controlled by developing fruits in Arabidopsis. Plant Physiol 106, 863-876

Hill, J. P. and Lord, E. M. (1988). Floral development in Arabidopsis thaliana: a comparison of the wild type and the homeotic pistillata mutant. Can. J. Bot. 67, 2922-2936.

Jack, T., Brockman, L. L. and Meyerowitz, E. M. (1992). The homeotic gene APETALA3 of Arabidopsis thaliana encodes a MADS box and is expressed in petals and stamens. Cell 68, 683-697.

Kempin, S. A., Savidge, B. and Yanofsky, M. F. (1995). Molecular basis of the cauliflower phenotype in Arabidopsis. Science 267, 522-525.

Liu, Y. G., Mitsukawa, N., Oosumi, T. and Whittier, R. F. (1995). Efficient isolation and mapping of Arabidopsis thaliana T-DNA insert junctions by thermal asymmetric interlaced PCR. Plant J. 8, 457-463.

Mandel, M. A., Gustafson-Brown, C., Savidge, B. and Yanofsky, M. F. (1992). Molecular characterization of the Arabidopsis floral homeotic gene APETALA1. Nature 360, 273-277.

Mandel, M. A. and Yanofsky, M. F. (1995). The Arabidopsis AGL8 MADS box gene is expressed in inflorescence meristems and is negatively regulated by APETALA1. Plant Cell 7, 1763-1771.

Martienssen, R. A. and Springer, P. (1997). Enhancer and gene trap transposons in Arabidopsis. In Insertional Mutagenesis: A Practical Approach (ed. G. Coupland). Academic Press (in press).

Müller, A. (1961). Zur Charakterisierung der Blüten und Infloreszenzen von Arabidopsis thaliana (L.) Heynh. Kulturpflanze 9, 364-393.

Ohad, N., Margossian, L., Hsu, Y.C., Williams, C., Repetti, P., and Fischer, R.L. (1996). A mutation that allows endosperm development without fertilization. Proc. Nat. Acad.Sci. USA 93, 5319-5324.

Okada, K., Komaki, M. K. and Shimura, Y. (1989). Mutational analysis of pistil structure and development of Arabidopsis thaliana. Cell Differ. Dev. 28, 27-38.

Petersen, M., Sander, L., Child, R., van Onckelen, H., Ulvskov, P. and Borkhardt, B. (1996). Isolation and characterization of a pod dehiscence zone-specific polygalacturonase from Brassica napus. Plant Mol. Biol. 31, $517-527$

Purugganan, M. D., Rounsley, S. D., Schmidt, R. J. and Yanofsky, M. F. 
(1995). Molecular evolution of flower development: diversification of the plant MADS-box regulatory gene family. Genetics 140, 345-356.

Rao, S. A., Mengesha, M. H. and Reddy, C. R. (1988). Characteristics, inheritance and allelic relationships of midribless mutants in pearl millet. $J$. Hered. 79, 18-20

Roe, J. L., Nemhauser, J. L. and Zambryski, P. C. (1997). TOUSLED participates in apical tissue formation during gynoecium development in Arabidopsis. Plant Cell 9, 335-353.

Rollins, R. C. (1993). The Cruciferae of Continental North America Systematics of mustard family from the Arctic to Panama. Stanford University Press: Stanford, California

Rounsley, S. D., Ditta, G. S. and Yanofsky, M. F. (1995). Diverse roles for MADS box genes in Arabidopsis development. Plant Cell 7, 1259-1269.

Schwarz-Sommer, Z., Huijser, P., Nacken, W., Saedler, H. and Sommer, H. (1990). Genetic control of flower development by homeotic genes in Antirrhinum majus. Science 250, 931-936.

Seip, L. and Tsuchiya, T. (1979). Trisomic analysis of a mutant gene ovl for ovaryless or male barley. Barley Genet. Newsl. 9, 89-90

Sessions, R. A. and Zambryski, P. C. (1995). Arabidopsis gynoecium structure in the wild type and in ettin mutants. Development 121, 15191532.
Smyth, D. R., Bowman, J. L. and Meyerowitz, E. M. (1990). Early flower development in Arabidopsis. Plant Cell 2, 755-767.

Springer, P. S., McCombie, W. R., Sundaresan, V. and Martienssen, R. A. (1995). Gene trap tagging of PROLIFERA, an essential MCM2-3-5-like gene in Arabidopsis. Science 268, 877-880.

Sundaresan, V., Springer, P., Volpe, T., Haward, S., Jones, J. D. G., Dean, C., Ma, H. and Martienssen, R. (1995). Patterns of gene action in plant development revealed by enhancer trap and gene trap transposable elements. Genes Dev. 9, 1797-1810.

Theißen, G. and Saedler, H. (1995). MADS-box genes in plant ontogeny and phylogeny: Haeckel's ‘biogenetic law’ revisited. Curr. Opin. Genet. Dev. 5 , 628-39.

Tsuge, T., Tsukaya, H. and Uchimiya, H. (1996). Two independent and polarized processes of cell elongation regulate leaf blade expansion in Arabidopsis thaliana (L.) Heynh. Development 122, 1589-1600.

Tsugeki, R., Kochieva, E. Z. and Fedoroff, N. V. (1996). A transposon insertion in the Arabidopsis SSR16 gene causes an embryo-defective lethal mutation. Plant J. 10, 479-489.

Yanofsky, M. F., Ma, H., Bowman, J. L., Drews, G. N., Feldmann, K. A. and Meyerowitz, E. M. (1990). The protein encoded by the Arabidopsis homeotic gene AGAMOUS resembles transcription factors. Nature 346, 35-39. 